\title{
Activation Difficult or Delayed
}

National Cancer Institute

\section{Source}

National Cancer Institute. Activation Difficult or Delayed. NCI Thesaurus. Code C63035.

Problem associated with delayed or difficult activation of the device. 